\title{
Phylogenetic Analysis of Selected RHDV Strains on the Basis of a Fragment of the Gene Encoding C-Terminal End of VP60 Capsid Structural Protein
}

Beata Hukowska-Szematowicz ${ }^{1 *}$, Beata Tokarz-Deptuła ${ }^{1}$, Wiesław Deptuła ${ }^{2}$

${ }^{1}$ Department of Immunology, Faculty of Biology, University of Szczecin, Felczaka 3c, 71-412 Szczecin, Poland

${ }^{2}$ Department of Microbiology, Faculty of Biology, University of Szczecin, Felczaka 3c, 71-412 Szczecin, Poland

\begin{abstract}
Phylogenetic analyses of RHDV provide information on the affinity of strains and point to evolutionary dependencies among them. The objective of the study was the phylogenetic analysis of six strains of RHD virus, including four Czech strains (CAMPV-351, CAMPV-561, CAMPV-562, CAMPV-558) and two French strains (Fr-1, Fr-2), on the basis of a fragment of the gene encoding C-terminal end of VP60 capsid structural protein. Phylogenetic analysis involved 25 sequences of RHDV homologues obtained from RHDV GenBank. The phylogenetic tree generated for 31 RHDV strains on the basis of a fragment of the gene encoding C-terminal end of VP60 capsid structural protein divided the strains analysed into four genetic groups (G1-G4), whereas the strains analysed were grouped in three genetic groups: G1 (CAMPV-351, CAMPV-562, CAMPV-558), G2 (Fr-1, Fr-2) and G3 (CAMPV-561). The phylogenetic analysis performed for Czech and French strains evidences that the strains feature different evolutionary paths and derive from European strains that caused foci of the plague in Germany and France. The obtained distribution of strains into four genetic groups testifies to their evolution, which is proved by group 4 gathering RHDVa strains.
\end{abstract}

Keywords: Rabbit haemorrhagic diseae virus (RHDV); Phylogenetic analysis; VP60

\section{Introduction}

RHD (Rabbit haemorrhagic disease) virus was first described in 1984 in China, where it caused viral haemorrhagic disease (VHD), which is very acute [1]. At present, the disease spread onto all continents, and is characterised with very high mortality, reaching up to $100 \%$. So far, various hypotheses have been described as regards the spread of the rabbit haemorrhagic disease virus (RHDV) worldwide and in Europe. Furthermore, studies on samples collected from rabbits deceased in the years 1950-1970 in the United Kingdom have indicated the presence of anti-RHD antibodies in serum and the presence of genetic material of the RHD virus in bone marrow [22]. These results point to the occurrence of the RHD virus in Europe long before the outbreak of the disease caused by the virus in China.

Phylogenetic analyses and the study on phylodynamics of RHDV strains has been the subject of many publications [2,3,5,7-9,1116,18-20,22-25,28-30]. The analyses performed indicate that RHDV strains are grouped depending on the time of strain isolation and on geographic location, and that the strains referred to as antigen variants RHDVa (new RHDVa subtype) are genetically distanced from the strains referred to as original RHDV subtype, which is manifested by formation of completely separate genetic groups. It must be pointed out that phylogenetic analyses of RHDV strains on the basis of a fragment of the gene encoding C-terminal end of VP60 capsid structural protein have so far been performed by researchers from France and Poland $[16,18,28]$. Phylogenetic studies by the French team $[16,18]$, who performed the analysis of 56 and 104 French RHDV strains from the years 1988-1995 and 1993-2000, as well as strains obtained from GenBank (including 5 RHDVa strains), indicated the distribution of the strains analysed into 3 and 6 genogroups (G1-G3, G1-G6), which differentiated with the time of strain isolation; whereas five analysed RHDVa strains (99-05, 00-Reu, Triptis, Hartmannsdorf, Iowa) were grouped in G6. In turn, Polish studies performed on the basis of analogical fragment, and involving six RHDV strains originating from the Central Europe (Eisenhuttenstadt, Frankfurt, Rossi, V-411, 24/89, 1447/96), from the years 1989-2002, indicated strain distribution into two genetic groups, while strain distribution in the groups correlated with geographic location and the time of isolation [28].
The objective of the study was to perform phylogenetic analysis of six European strains of RHD virus, including four Czech strains (CAMPV-351, CAMPV-561, CAMPV-562, CAMPV-558) and two French strains (Fr-2, Fr-2), on the basis of a fragment of the gene encoding C-terminal end of VP60 capsid structural protein. The results of own studies were compared with 25 sequences of RHDV homologues obtained from GenBank.

\section{Materials and Methods \\ RHDV strains}

The study involved four Czech strains (CAMPV-351 from 1987 (passage from 2000), CAMPV-561 from 1996, CAMPV-562 from 1992, CAMPV-558 from 1988) and two French strains (Fr-1 from 1994, Fr-2 from 1992) (Table 2), prepared in the form of lyophylisate according to the procedure previously described by Fitzner et al. [6]. Czech strains originated from the Collection of Animal Pathogenic Microorganisms, Veterinary Research Institute in Brno (Czech Republic), while French strains were obtained from CNEVA- Laboratoire Central de Recherches Avicole et Porcine, Poulfragan, from Dr J. P. Morisse.

\section{Isolation of viral RNA}

RNA of RHD virus was isolated from lyophylisates using the RNA set Total RNA (A\&A Biotechnology, Poland) according to the provided protocol.

\section{Reverse transcription (RT) reaction-cDNA synthesis}

Complementary cDNA strand were obtained on a matrix of viral RNA, using reverse transcriptase enzyme (M-MLV Reverse

*Corresponding author: Beata Hukowska-Szematowicz, Department of Immunology, Faculty of Biology, University of Szczecin, Felczaka 3c, 71-412 Szczecin, Poland, Tel: +48914441592; Fax: +48914441606; E-mail: beatahsz@gmail.com

Received July 11, 2014; Accepted August 01, 2014; Published August 10, 2014

Citation: Hukowska-Szematowicz B, Tokarz-Deptuła, Deptuła W (2014) Phylogenetic Analysis of Selected RHDV Strains on the Basis of a Fragment of the Gene Encoding C-Terminal End of VP60 Capsid Structural Protein. J Phylogen Evolution Biol 2: 130. doi:10.4172/2329-9002.1000130

Copyright: (c) 2014 Tokarz-Deptuła B, et al. This is an open-access article distributed under the terms of the Creative Commons Attribution License, which permits unrestricted use, distribution, and reproduction in any medium, provided the original author and source are credited. 
Transciptase, Invitrogen, USA). $25 \mu \mathrm{l}$ of the reaction mixture contained: $1.0 \mu \mathrm{l}$ of specific antisense starter (P5) at $100 \mu \mathrm{M}$ concentration (Metabion $\mathrm{GmbH}$, Germany), $1.0 \mu \mathrm{l}$ of dNTPs nucleotide blend at 25 $\mathrm{mM}$ concentration (Promega, USA), $0.5 \mu \mathrm{l}$ of reverse transcriptase enzyme M-MLV RT (Invitrogen, USA), $2.0 \mu$ l of 5 -fold concentrated RT-PCR buffer (Invitrogen, USA), $0.5 \mu$ LTT $0.1 \mathrm{M}$ (Invitrogen, USA), $1.0 \mu \mathrm{l}$ RNase inhibitor RNase OUT (Invitrogen, USA), $14 \mu \mathrm{l}$ of water for molecular biology (Eppendorf, Germany) and $5.0 \mu$ l of RNA of an appropriate RHD virus strain. Before reaction mixture was prepared, RNA of five tested RHDV strains was heated for 5 minutes at $65^{\circ} \mathrm{C}$, and then stored on ice until the mixture was prepared. RT-PCR reaction was conducted in a T-gradient Thermocycler (Biometra, Germany) using the following temperature-time profile: $25^{\circ} \mathrm{C}$ for 10 minutes, $37^{\circ} \mathrm{C}$ for 60 minutes, $95^{\circ} \mathrm{C}$ for 5 minutes and $4^{\circ} \mathrm{C}$ for 1 minute. Resulting cDNA was stored at the temperature of $2-8^{\circ} \mathrm{C}$ for further analyses.

\section{Starters}

Starters suggested by Guittre [10] were used, based on complete sequence of the RHDV-FRG genome, developed by Meyers et al. [21], and allowing for amplification of a fragment of the gene encoding C-terminal end of VP60 capsid structural protein. Using starters: P6 (sense) 5'acccagtcaggcaccaggctg3' and P5 (antisense) 5 'gcacctgcaagtccaatccg3', a 320bp fragment was amplified. Starter synthesis was performer by Metabion GmbH (Germany).

\section{PCR}

$50 \mu \mathrm{l}$ of the reaction mixture contained: $2.0 \mu \mathrm{l}$ of starters $(1.0 \mu \mathrm{l}$ of each P6P5) at $10 \mu \mathrm{M}$ concentration each (Metabion GmbH, Germany), $1.0 \mu \mathrm{l}$ of dNTPs blend at $10 \mathrm{mM}$ concentration (Promega, USA), 5.0 $\mu \mathrm{l}$ of 10-fold concentrated Taq Plus buffer (GenoPlast, Poland), $1.0 \mu \mathrm{l}$ of Taq Plus DNA polymerase (GenoPlast, Poland), $1.0 \mu \mathrm{l}$ of 10 -fold concentrated Mg buffer (Promega, USA), $38.0 \mu \mathrm{l}$ of water for molecular biology (Eppendorf, Germany) and $2.0 \mu \mathrm{l}$ of cDNA of an appropriate RHD virus strain (added to the reaction at the end). RT-PCR reaction was conducted in a T-gradient Thermocycler (Biometra, Germany). The following temperature-time profile was used: preliminary denaturation $94^{\circ} \mathrm{C}-2$ minutes, 35 cycles involving: denaturations $\left(94^{\circ} \mathrm{C}-30\right.$ seconds), starter affixing $\left(50^{\circ} \mathrm{C}, 53^{\circ}\right.$ or $55^{\circ} \mathrm{C}$-depending on the strain- 1 minute), chain elongation $\left(72^{\circ} \mathrm{C}-2\right.$ minutes), final elongation ( $72^{\circ}$ for 5 minutes) and cooling the reaction mixture to $4^{\circ} \mathrm{C}$. Reaction products were stored at the temperature of $4^{\circ} \mathrm{C}$ for further analyses.

\section{Electrophoresis of PCR products}

For the purpose of visualisation of PCR products, electrophoresis was performed in $1.5 \%$ agarose gel (Prona, USA) dyed with ethidium bromide (Fermentas, Lithuania). Molecular mass marker GeneRuler 100 and 50 (Fermentas, Lithuania) was used for evaluation of size of products. Electrophoretic separation was conducted in 1.0-fold

\begin{tabular}{|c|c|c|c|c|c|}
\hline & No. & RHDV strain & Country of origin & Year isolated & $\begin{array}{c}\text { GenBank } \\
\text { Accesion Number }\end{array}$ \\
\hline \multirow{32}{*}{ 웅 } & 1. & V-351 & Czech Republic & 1987 (passage from 2000) & In preparation for submission to GenBank \\
\hline & 2. & CAMPV-561 & Czech Republic & 1996 & FJ231995 \\
\hline & 3. & CAMPV-562 & Czech Republic & 1992 & FJ231996 \\
\hline & 4. & CAMPV-558 & Czech Republic & 1988 & FJ231997 \\
\hline & 5. & Fr-1 & France & 1994 & FJ231998 \\
\hline & 6. & Fr-2 & France & 1992 & FJ231999 \\
\hline & 7. & Eisenhuttenstadt & \multirow{6}{*}{ Germany } & 1989 & Y15440 \\
\hline & 8. & FRG & & 1989 & M67473 \\
\hline & 9. & Meiningen & & 1993 & Y15426 \\
\hline & 10. & Jena & & 1993 & EF558576 \\
\hline & 11. & Frankfurt & & 1996 & Y15424 \\
\hline & 12. & Wriezen & & 1996 & Y15427 \\
\hline & 13. & Haute Saone & \multirow{8}{*}{ France } & 1988 & U49726 \\
\hline & 14. & SD & & 1989 & Z29514 \\
\hline & 15. & $95-05$ & & 1995 & AJ535092 \\
\hline & 16. & $95-10$ & & 1995 & AJ535094 \\
\hline & 17. & $99-05$ & & 2005 & AJ302016 \\
\hline & 18. & $00-13$ & & 2000 & AJ495856 \\
\hline & 19. & 00-REU & & 2000 & AJ303106 \\
\hline & 20. & $03-24$ & & 2003 & AJ969628 \\
\hline & 21. & BS89 & \multirow[b]{2}{*}{ Italy } & 1989 & X87607 \\
\hline & 22. & Italy90 & & 1990 & EU003579 \\
\hline & 23. & AST89 & Spain & 1989 & Z49271 \\
\hline & 24. & Rainham & United Kingdom & 1993 & AJ006019 \\
\hline & 25. & WX/China/1984 & \multirow[t]{2}{*}{ China } & 1984 & AF402614 \\
\hline & 26. & Whn/China/01/05 & & 2005 & DQ069280 \\
\hline & 27. & KV0801 & Korea & 2008 & FJ212322 \\
\hline & 28. & Bahrain & Bahrain & 2001 & DQ189077 \\
\hline & 29. & lowa 2000 & \multirow{3}{*}{ USA } & 2000 & AF258618 \\
\hline & 30. & NY-01 & & 2001 & EU003581 \\
\hline & 31. & UT-01 & & 2001 & EU003582 \\
\hline & 32. & $\mathrm{RCV}$ & Italy & 1996 & X96868 \\
\hline
\end{tabular}

Table 1: RHDV and RCV strains used for phylogenetic analysis. 
concentrated TBE buffer, at room temperature, with current voltage of $100 \mathrm{~V} / \mathrm{cm}$ of gel for 45 minutes, using a set for electrophoresis (Bio-Rad, Germany). Storage and interpretation of results was completed using a UV visualisation set (Vilber Lourmat, France).

Preparative amplification, purification and preparation of analysed fragments of RHD virus genome for sequencing

Following PCR results visualisation, mass PCR was performed along with electrophoretic separation, using conditions identical as those described above. Next, DNA isolation from gel was performed using a Gel OUT set (A\&A Biotechnology, Poland) according to the manufacturer's recommended procedure. Such prepared samples were sent for automatic sequencing to Metabion $\mathrm{GmbH}$, Germany, and to DNA Sequencing and Oligonucleotide Synthesis Laboratory of the Institute of Biochemistry and Biophysics at the Polish Academy of Sciences, Warsaw, Poland.

\section{Comparative analysis of nucleotide sequences, creation of homology matrix and phylogenetic tree}

The obtained nucleotide sequences of a VP60 protein-coding gene C-terminal region fragment from six tested RHDV strains (CAMPV-351, CAMPV-561, CAMPV-562, CAMPV-558, Fr-1, Fr-2) were compared to one another (alignment) and to 25 homologous sequences of RHDV obtained from GenBank, whereas RCV strain served for rooting of the phylogenetic tree Table 1 . The comparative analysis of the sequences was performed in DNAMAN software version 5.2.10 (Lynnon BioSoft, Canada). On the basis of the comparison of the nucleotide sequences of RHDV strains in DNAMAN software homology matrices were created, the basis of which was formed by common elements between the two sequences compared. The values from the matrices created have been graphically transformed into phylogenetic trees revealing hypothetical affinity and evolutionary dependences among the strains analysed. The tree was created using the maximum likelihood (ML) model. Each of the phylogenetic trees generated was a rooted tree, and the out group was formed by the sequence of the RCV virus (X96868). Bootstrap method was used for the assessment of the phylogenetic tree generated by the software.

\section{Results}

PCR yielded amplification of 320bp long genome fragment which was subsequently sequenced. Obtained sequences of six analysed strains (CAMPV-351, CAMPV-561, CAMPV-562, CAMPV-558, Fr-1, Fr-2) of RHDV were submitted to GenBank (except for CAMPV-351, which has been prepared for submission) Table 1. Obtained nucleotide sequences of six strains (CAMPV-351, CAMPV-561, CAMPV-562, CAMPV-558, Fr-1, Fr-2) of RHDV were compared to 25 sequences of RHDV homologues (Table 1). The phylogenetic tree (Figure 1) generated for 31 RHDV strains on the basis of a fragment of the gene encoding C-terminal end of VP60 capsid structural protein divided the strains analysed into four genetic groups (G1-G4), whereas the strains

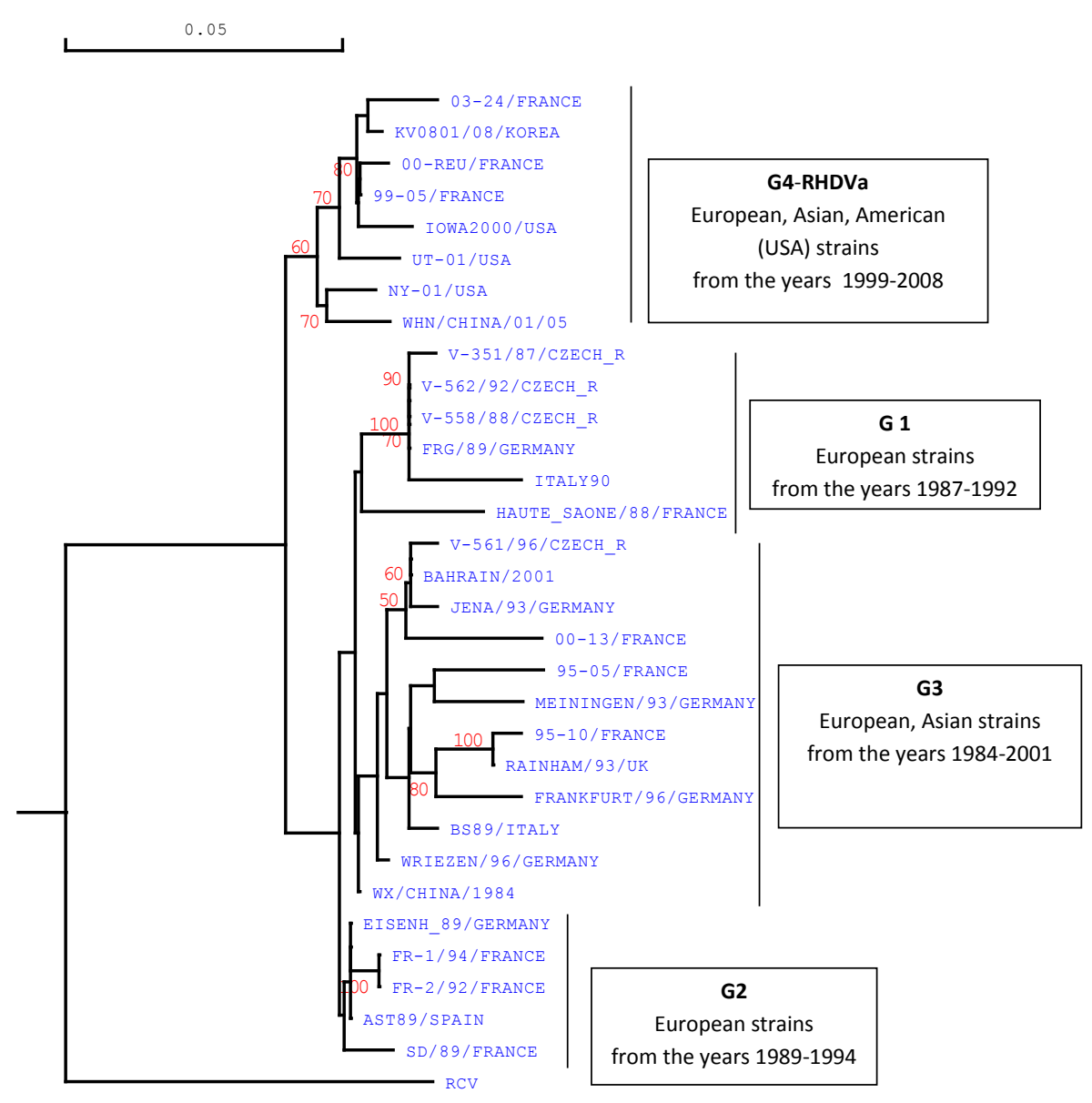

Figure 1: Phylogenetic tree on the basis of comparison of nucleotide sequences of the fragment of gene encoding C-terminal part of VP60 protein created with the maximum likelihood (ML) method. 


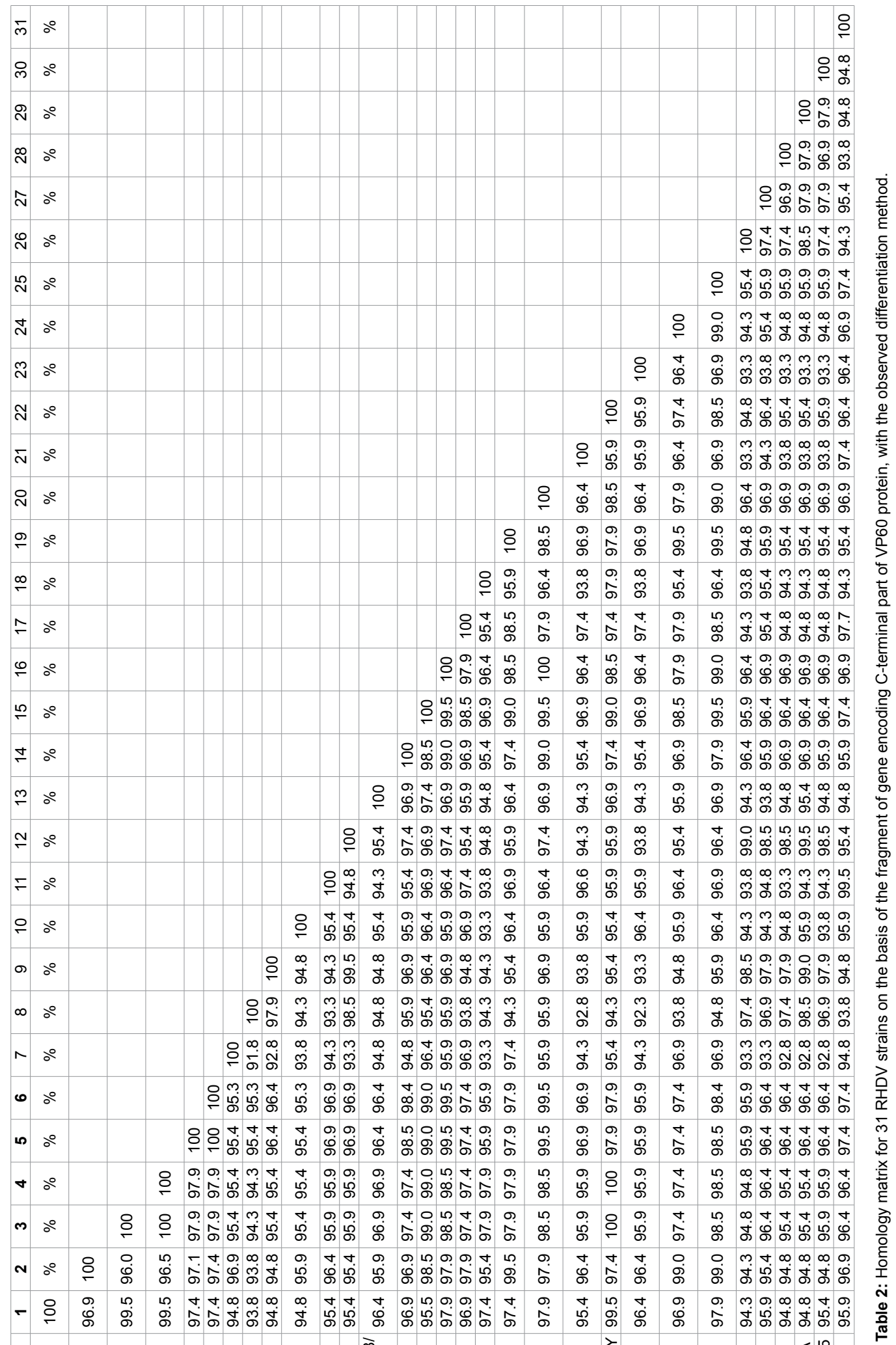

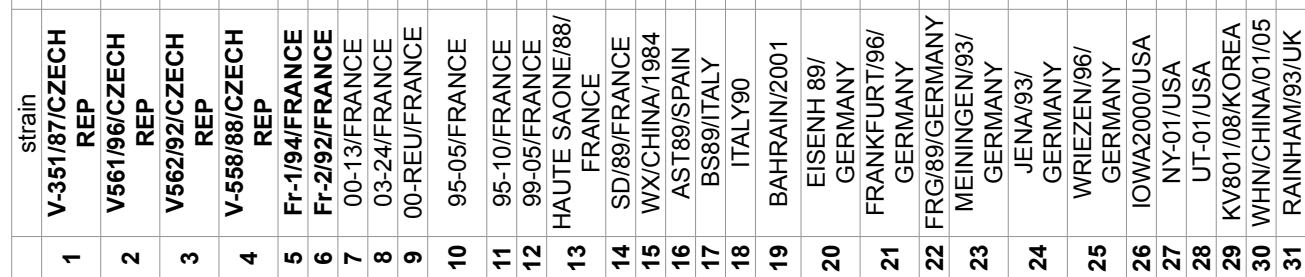


analysed were grouped in three genetic groups: G1 (CAMPV-351, CAMPV-562, CAMPV-558), G2 (Fr-1, Fr-2) and G3 (CAMPV-561).

Genetic group one (G1) comprised just three European strains from the years 1987-1992, including the analysed Czech strains CAMPV-351, CAMPV-562 and CAMPV-V-558, as well as strains obtained from GenBank, namely German FRG, Italian ITALY90, and French HAUTE SAONE strain. Genetic group two (G2) also gathered European strains from the years 1989-1994, including the analysed French strains Fr-1 and Fr-2, as well as three strains obtained from GenBank, namely German Eisenhitennstadt, Spanish AST89, and French SD strain. The largest genetic group was group three (G3), which apart from the analysed Czech V-561 strain from 1996 included 11 strains from the years 19842001 obtained from GenBank, such as German: Jena93, Meiningen93, Frankfurt96, Wriezen96; French: 00-13, 95-05, 95-10; British Rainham; Italian BS89; as well as Bahrain and WX/China strains. Genetic group four (G4) comprised European, Asian and American strains from the years 1999-2008, namely eight strains, including three French strains: 03-24, 00-Reu, 99-05; three American: Iowa 2000, UT-01, NY-01; one Korean 0801/08, and one Chinese strain WHN. Bootstrap value in the tree generated amounted from $50 \%$ to $100 \%$.

When analysing the homology matrix (Table 2) generated for 31 RHDV strains, it can be stated that homology determined on the basis of a fragment of the gene encoding C-terminal end of VP60 capsid structural protein among the strains in particular genetic groups was as follows: in G1: $94.8 \%-100 \%$, in G2: $97.9-100 \%$, in G3: $93.8-99.5 \%$, while in G4: 96.9-99.5\%. Furthermore, it was determined that strains V-562 and V-558 belonging to G1 revealed 100\% sequence homology in the analysed gene fragment, as well as $100 \%$ homology as compared to the German FRG strain. In genogroup G2, also 100\% homology was recorded for Fr-1 and Fr-2 strains; moreover, the strains revealed $99.5 \%$ homology with the Spanish AST89 strain. In turn, in genogroup G3, the highest homology of the nucleotide sequence, amounting to $99.5 \%$, was observed for Czech CAMPV-561 strain as compared to Bahrain strain. In genogroup G4, the highest homology of $99.5 \%$ was recorded between KV0801 and 00-Reu strains on the one hand and 99-05 strain on the other, originating from Korea and France, respectively.

\section{Discussion}

The obtained distribution into genetic groups corresponds to the view according to which strains in the groups are linked by the time of their isolation rather than geographic origin $[6,18,19]$. In this respect, however, antigen variants differ, as they are always located in one genetic group $[4,5,14,16,20,26]$. In the case of genetic group one (G1), one can clearly define the criterion according to which the strains formed the group. It was formed of European strains from the Czech Republic, Germany, Italy and France, in the vast majority isolated in the years 1987-1989, namely upon the occurrence of the plague in Europe, with bootstrap value of $100 \%$. This genetic group can be referred to as a "cluster" because it gathers strains having a common identification time, regardless of their geographic origin. Such positioning of strains in G1 corresponds to the results previously obtained by LeGall-Recule et al. $[16,18]$, according to which strains in genogroups follow the time of isolation pattern, whereas strains isolated at a similar time are characterised by high homology. Detailed evolutionary relations in this group point to the fact that most strains in this group, except for French Haute Saone88 strain, derive from CAMPV-351, which is reflected in epizootic analysis of the plague in Europe in the years 1987-1989. A very similar relation can be observed in the case of G2, which comprised the analysed French Fr-1 and Fr-2 strains together with the strains isolated in 1989 in Spain and Italy (AST89 and SD/89). Evolutionary relations between the analysed Fr- 1 and Fr-2 strains, supported with $100 \%$ homology between them (Table 2), indicate that these can be two "isolates" of the very same French strain, isolated in the same focus of the disease in the years 1992-1994. Genetic group three (G3) included strains from the years 1984-2001, which allows for suspecting that the evolutionary path of the Czech CAMPV-561 strain from 1996 led across Germany, and perhaps the strain derives from Jena strain from 1993 or Wriezen from 1996 (99.0\% homology). Other strains in this group have common time of isolation. Strains originating from Europe, Asia and the USA, being antigen variants RHDVa (03-24, KV0801/08, 00-Reu, 99-05, Iowa, UT-01, NY-01,WHN) formed the fourth genetic group (G4) with homology ranging from $91.3 \%$ to $98.9 \%$, which corresponds to genogroup 6 described by Le Gall et al. [18].

\section{Conclusion}

Since the identification of RHDV, its evolutionary paths have been traced, which is favoured by the emergence of increasingly new RHDV strains. Before, however, "new strains" appeared in the evolution tunnel, there must have been "older" strains from which it all started. According to one of the theories on virus evolution [27], RHDV strains will keep evolving, and this phenomenon will be manifested by new strains of the virus, which can nowadays be evidenced by French strain referred to as French RHD variant from 2010 [17], which is much different from the original RHDV subtype and the new RHDVa subtype, and its occurrence suggests differentiation of a new group of RHDV strains. Therefore, in view of these facts, it seems justified to analyse even the older RHDV strains from the years 1988-1996, as this allows for learning the true history of RHDV evolution, and perhaps will allow for analysing the evolution of RNA viruses. The phylogenetic analysis performed in own study for six RHDV strains, including four Czech (CAMPV-351, CAMPV-561, CAMPV-562, CAMPV-558) and two French (Fr-1, Fr-2) strains, on the basis of a fragment of the gene encoding C-terminal end of VP60 capsid structural protein, evidences that the strains feature different evolutionary paths and derive from European strains that caused foci of the disease in Germany and France. The obtained distribution of strains into four genetic groups testifies to their evolution, which is proved by group 4 gathering RHDVa strains.

\section{Acknowledgment}

This work was financially supported by Grant No. 2 P06K 02927 from Polish National Science Center.

\section{References}

1. Abrantes J, van der Loo W, Le Pendu J, Esteves PJ (2012) Rabbit haemorrhagic disease (RHD) and rabbit haemorrhagic disease virus (RHDV): a review. Vet Res 43: 12.

2. Alda F, Gaitero T, Suárez M, Merchán T, Rocha G, et al. (2010) Evolutionary history and molecular epidemiology of rabbit haemorrhagic disease virus in the Iberian Peninsula and Western Europe. BMC Evol Biol 10: 347.

3. Chrobocinska M. Mizak B (2007) Phylogenetic analysis of partial capsid protein gene of rabbit haemorrhagic disease virus (RHDV) strains isolated between 1993 and 2005 in Poland. Bull Vet Inst Pulawy 51: 189-197.

4. Farnos O, Rodriquez D, Valdes O, Chiong M, Parra F, et al. (2007) Molecular and antigenic characterization of rabbit hemorrhagic disease virus isolated in Cuba indicates a distinct antigenic subtype. Arch Virol 152: 1215-1221.

5. Fitzner A, Kesy A (2003) Variability of Polish isolates of the RHD virus (in Polish). Medycyna Wet 59: 905-908

6. Fitzner A, Kesy A, Niedbalski W, Paprocka G, Walkowiak B: The identification of polypeptide VP60 national isolates of the RHD virus (in Polish). Medycyna Wet.,1996, 52, 303-305.

7. Fitzner A, Niedbalski W, Paprocka G, Kesy A (2012) Identification of Polish RHDVa subtype strains based on the analysis of a highly variable part of VP60 gene. Pol J Vet Sci 15: 21-29. 
Citation: Hukowska-Szematowicz B, Tokarz-Deptuła, Deptuła W (2014) Phylogenetic Analysis of Selected RHDV Strains on the Basis of a Fragment of the Gene Encoding C-Terminal End of VP60 Capsid Structural Protein. J Phylogen Evolution Biol 2: 130. doi:10.4172/2329-9002.1000130

Page 6 of 6

8. Forrester NL, Abubakr MI, Abu Elzein EM, Al-Afaleq Al, Housawi FM, et al. (2006) Phylogenetic analysis of rabbit haemorrhagic disease virus strains from the Arabian Peninsula: did RHDV emerge simultaneously in Europe and Asia? Virology 344: 277-282.

9. Forrester NL, Boag B, Moss SR, Turner SL, Trout RC, et al. (2003) Long-term survival of New Zealand rabbit haemorrhagic disease virus RNA in wild rabbits revealed by RT-PCR and phylogenetic analysis. J Gen Virol 84: 3079-3086.

10. Guittré C, Ruvoen-Clouet N, Barraud L, Cherel Y, Baginski I, et al. (1996) Early stages of rabbit haemorrhagic disease virus infection monitored by polymerase chain reaction. Zentralbl Veterinarmed B 43: 109-118.

11. Hukowska-Szematowicz B (2006) Immunological-genetic characteristics of chosen strains of RHD (rabbit haemorrhagic disease) virus (in Polish). PhD dissertation, University of Szczecin, Poland

12. Hukowska-Szematowicz B, Deptula W (2010) Phylogenetic analysis of French strains of the RHD virus on the basis of a fragment of gene encoding C-terminal part of structural capsid VP60 protein. Adv Agric Science 12: 159-168.

13. Hukowska-Szematowicz B, Pawlikowska M, DeptuÅ,a W (2009) Genetic variability of Czech and German RHD virus strains. Pol J Microbiol 58: 237-245.

14. Kerr PJ, Kitchen A, Holmes EC (2009) Origin and phylodynamics of rabbit hemorrhagic disease virus. J Virol 83: 12129-12138.

15. Kinnear M, Linde CC (2010) Capsid gene divergence in rabbit hemorrhagic disease virus. J Gen Virol 91: 174-181.

16. Le Gall G, Arnauld C, Boilletot E, Morisse JP, Rasschaert D (1998) Molecular epidemiology of rabbit haemorrhagic disease virus outbreaks in France during 1988 to 1995. J Gen Virol 79 : 11-16.

17. Le Gall-Reculé G, Zwingelstein F, Boucher S, Le Normand B, Plassiart G, et al. (2011) Detection of a new variant of rabbit haemorrhagic disease virus in France. Vet Rec 168: 137-138.

18. Le Gall-Reculé G, Zwingelstein F, Laurent S, de Boisséson C, Portejoie Y, et al. (2003) Phylogenetic analysis of rabbit haemorrhagic disease virus in France between 1993 and 2000, and the characterisation of RHDV antigenic variants. Arch Virol 148: 65-81.

19. Matiz K, Ursu K, Kecskeméti S, Bajmócy E, Kiss I (2006) Phylogenetic analysis of rabbit haemorrhagic disease virus (RHDV) strains isolated between 1988 and 2003 in eastern Hungary. Arch Virol 151: 1659-1666.
20. McIntosh MT, Behan SC, Mohamed FM, Lu Z, Moran KE, et al. (2007) A pandemic strain of calicivirus threatens rabbit industries in the Americas. Virol J 4: 96.

21. Meyers G, Wirblich C, Thiel HJ (1991) Rabbit hemorrhagic disease virusmolecular cloning and nucleotide sequencing of a calicivirus genome. Virology 184 : 664-676.

22. Moss SR, Turner SL, Trout RC, White PJ, Hudson PJ, et al. (2002) Molecular epidemiology of Rabbit haemorrhagic disease virus. J Gen Virol 83: 2461-2467.

23. Muller A, Freitas J, Silva E, Le Gall-Reculé G, Zwingelstein F, et al. (2009) Evolution of rabbit haemorrhagic disease virus (RHDV) in the European rabbit (Oryctolagus cuniculus) from the Iberian Peninsula. Vet Microbiol 135: 368-373.

24. Niedzwiedzka-Rystwej P, Pawlikowska M, Hukowska-Szematowicz B, TokarzDeptula B, Deptula W (2009) Immunological and genetic studies of RHD (rabbit haemorrhagic disease) virus strains. Cent Eur J Immunol 34: 61-67.

25. Nowotny N, Bascuñana $C R$, Ballagi-Pordány $A$, Gavier-Widén $D$, Uhlén $M$, et al. (1997) Phylogenetic analysis of rabbit haemorrhagic disease and European brown hare syndrome viruses by comparison of sequences from the capsid protein gene. Arch Virol 142: 657-673.

26. Oem JK, Lee KN, Roh IS, Lee KK, Kim SH, et al. (2009) Identification and characterization of rabbit hemorrhagic disease virus genetic variants isolated in Korea. J Vet Med Sci 71: 1519-1523.

27. Patel MR, Emerman M, Malik HS (2011) Paleovirology - ghosts and gifts of viruses past. Curr Opin Virol 1: 304-309.

28. Pawlikowska M, Hukowska-Szematowicz B, Deptula W (2009) Genetic characteristic of six strains of RHD (Rabbit haemorrhagic disease) virus orginating from Europe. Centr Eur J Immunol 34 :7-13.

29. Pawlikowska M, Hukowska-Szematowicz B, Deptula W (2010) Phylogenetic analysis of selected strains of Rabbit haemorrhgaic disease virus on the basis of $\mathrm{N}$-terminal fragment of the gene encoding structural protein VP60. Bull Vet Inst Pulawy 54: 129-133.

30. Wang X, Hao H, Qiu L, Dang R, Du E, et al. (2012) Phylogenetic analysis of rabbit hemorrhagic disease virus in China and the antigenic variation of new strains. Arch Virol 157: 1523-1530. 